\title{
Indigenous Agricultural Revolution. Paul Richards, Hutchinson, 1985, 192 pp.
}

Pascale Maizi

\section{(2) OpenEdition}

1 Journals

\section{Édition électronique}

URL : http://journals.openedition.org/apad/3273

DOI : 10.4000/apad.3273

ISSN : 1950-6929

Éditeur

LIT Verlag

Édition imprimée

Date de publication : 1 juin 1993

\section{Référence électronique}

Pascale Maizi, «Indigenous Agricultural Revolution. Paul Richards, Hutchinson, 1985, 192 pp. »,

Bulletin de l'APAD [En ligne], 5 | 1993, mis en ligne le 04 juin 2008, consulté le 21 septembre 2020. URL: http://journals.openedition.org/apad/3273 ; DOI : https://doi.org/10.4000/apad.3273

Ce document a été généré automatiquement le 21 septembre 2020.

Bulletin de l'APAD 


\title{
Indigenous Agricultural Revolution. Paul Richards, Hutchinson, 1985, $192 \mathrm{pp}$.
}

\author{
Pascale Maizi
}

1 Sur la base d'expériences de terrain en Sierra Leone et au Nigeria, Paul Richards critique les présupposés des opérateurs de développement. Il montre d'abord que l'intérêt actuel pour les pratiques paysannes ne découle pas d'un progrès de la connaissance scientifique, mais d'un a priori populiste qui domine à certaines époques : en Sierra Leone, dès 1930, l'analyse de la jachère est faite et on propose des systèmes d'accompagnement des dynamiques paysannes: toute l'actuelle "Recherche-Développement" est là. Cette tendance est balayée dans les années 1940 par le modèle intensif/technocratique, sous la pression de Londres. La négation des pratiques paysannes correspond à des intérêts extérieurs au monde rural.

2 Richards montre ensuite la cohérence interne et les capacités autonomes d'évolution des systèmes agraires africains. Les agricultures africaines témoignent d'une connaissance écologique fine des conditions locales et de logiques de minimisation du risque et de diversification des cultures. En particulier, les cultures associées, formes spécifiques d'intensification des agricultures africaines, peuvent, selon, lui être la base d'une "révolution agricole endogène". Deux études de cas lui permettent de montrer que la spécialisation vivrière ne signifie pas archaïsme, que les agricultures s'adaptent vite, mais que le changement non-planifié échappe aux intervenants extérieurs. La spécificité des systèmes de production est telle que tout "paquet technique" est forcément inopérant. La capacité d'innover est une composante structurelle de toute agriculture, et c'est une ressource pour les opérations de développement.

3 A l'opposé, les apports de la science et du développement paraissent faibles: les innovations majeures sont dues aux paysans et la "science" ne fait que suivre. La science et le développement se basent souvent sur des présupposées faux ou non adaptés, sur des modèles écologiques trop simples. Les centres de recherches internationaux, spécialisés par culture, sont incapables de prendre en compte les 
spécificités locales. La déconnexion complète entre "recherche paysanne" et "recherche officielle", entre secteurs "formel" et "informel" du développement est préjudiciable. Il préconise une "recherche-développement" qui ne se limite pas aux systèmes techniques de production mais prenne en compte l'environnement économique, qui soit en synergie avec les savoirs et les dynamiques paysannes, et où le secteur "formel" de la recherche se limite à ce qui dépasse les capacités paysannes. Une telle approche demande un diagnostic basé sur l'observation participante, avec des méthodes proches de celles de l'anthropologue. 